\title{
(อ) \\ Informing critical care drug requirements in response to the COVID-19 pandemic
} OPEN ACCESS

\author{
Anita Hogg 자, ${ }^{1}$ Rachel Huey ำ , Michael G Scott, ${ }^{1}$ Andrew Ferguson ${ }^{2}$
}

${ }^{1}$ Medicines Optimisation Innovation Centre, Northern Health and Social Care Trust, Antrim, UK

${ }^{2}$ Intensive Care Medicine Dept, Belfast Health and Social Care Trust, Belfast, UK

\section{Correspondence to} Anita Hogg, Medicines Optimisation Innovation Centre, Northern Health and Social Care Trust, Antrim BT41 2RL, UK; anita.hogg@ northerntrust.hscni.net

Received 14 May 2020 Revised 3 June 2020

Accepted 8 June 2020 Published Online First 13 July 2020

EAHP Statement 2: Selection, Procurement and Distribution. EAHP Statement 4: Clinical Pharmacy Services. EAHP Statement 5: Patient Safety and Quality Assurance. EAHP Statement 6: Education and Research.
Check for updates

(C) European Association of Hospital Pharmacists 2020. Re-use permitted under CC BY-NC. No commercial re-use. Published by BMJ.

To cite: Hogg A, Huey $R$,

Scott MG, et al.

Eur J Hosp Pharm

2020:27:263-266.

\section{ABSTRACT \\ Objectives The main aim was to develop a process} to estimate critical care drug requirements to robustly inform regional procurement planning and preparedness in response to the COVID-19 pandemic. The objectives were to identify critical care drugs required, obtain patient usage data and consider current regional practice to establish the requirement.

Method Health and Social Care (HSC) Trusts across Northern Ireland (NI) identified critical care drugs required and an estimation of average daily usage data. The Microsoft Excel database was constructed to compile Trust data and establish regional requirement. The database was refined further according to real-world data from NI HSC Trusts, Intensive Care National Audit and Research Centre report on COVID-19 in critical care, daily regional COVID-19 figures and other available National data. Components of a tool originally developed for H1N1 and updated for COVID-19 were adapted to reflect the $\mathrm{NI}$ context and used in the regional database. The database was clinically reviewed to ensure that it accurately reflected current regional practice given the evolving nature of the pandemic.

Results The critical care drugs required in the pandemic, usage data and current regional practice were identified to establish requirement. A regional database was constructed and used to produce a model for calculating approximate critical drug requirements. The model was used to map critical drug requirements to available stock in Trusts and wholesalers/suppliers, enabling the identification of treatment capacity for these medicines regionally, both currently and for projected surges. Data have also been used in the preparation of weekly regional situation reports provided to both the HSC Board and the Department of Health.

Conclusion The process developed is a robust approach to assist in informing regional critical care drug requirements in response to the COVID-19 pandemic. Further application has been demonstrated in regional procurement planning and preparedness.

\section{INTRODUCTION}

The COVID-19 pandemic is the single greatest challenge to face healthcare, worldwide, since the Asian Flu in 1957. In the UK, more than 21000 deaths in hospital have now been associated with the virus. ${ }^{1}$

Widespread social and healthcare-related interventions and measures have been introduced by the UK government to reduce morbidity and mortality associated with this infection. Social measures imposed include social distancing, self-isolation and lockdown; healthcare measures incorporate escalating resources and capacity within the National
Health Service and other services to meet demand and the anticipated surge. These interventions are on a scale never before witnessed.

Pharmaceutical interventions and medicines optimisation are essential components of the healthcare response to COVID-19. Medicines are a clinical priority and are required to support both patients and front-line clinical staff in their efforts to deal with the virus and to optimise patient care. As a result, there has been an unprecedented global demand on supportive medicines, particularly in critical care.

Assuring the availability of critical medicines at the point of need during a pandemic is particularly complex. The balance between 'normal' supply and demand is eroded as demand escalates and organisations may order excess stock to maintain continuity of supply, placing further pressure on already constrained medicines and the supply chain. Fair and equitable distribution of available stock is also a challenge.

A collaborative approach to planning is required, between manufacturers, wholesalers/suppliers, health departments, Trusts and medicines procurement specialists. A key component of this is to estimate critical drug requirements to meet demand both currently and for the anticipated surge.

\section{AIM}

To develop a process to estimate critical care drug requirements to robustly inform procurement planning and preparedness in response to the COVID-19 pandemic.

\section{OBJECTIVES}

- Identify critical care drugs required regionally in the COVID-19 pandemic.

- Obtain regional usage data for these drugs and consider current regional practice to establish requirement.

\section{METHODOLOGY}

Health and Social Care (HSC) Trusts across Northern Ireland (NI) identified critical care drugs required in the pandemic and provided an estimation of average daily usage data for these drugs per patient. A Microsoft Excel database was constructed to compile the Trust data and to establish the regional requirement for critical care drugs. Any gaps in dosage data were populated with typical British National Formulary daily doses for an $80 \mathrm{~kg}$ adult requiring ventilation in intensive care. ${ }^{2}$

The database was refined further according to real-world data from NI HSC Trusts, the 17 April 2020 Intensive Care National Audit and Research 
Centre report on COVID-19 in critical care (including data from England, Wales and NI), daily regional COVID-19 figures published by the NI Department of Health and other National data available at the time. ${ }^{34}$

An unpublished tool originally developed to assist in predicting critical care medicine requirements for the H1N1 swine influenza 2009 pandemic and subsequently updated for COVID-19 using published data from China (Borthwick, Barton and GrahamClarke, 2020), was considered for use as an aid to inform critical care drug requirements in response to the COVID-19 pandemic. The following components of the tool were used in the regional database:

- Patient and treatment characteristics assumptions, that is, percentage uptake of drug group, treatment duration for each drug and typical length of intensive care unit (ICU) stay.

- Local practice adjustments, that is, drug dosages and percentage usage within a drug group, which were subsequently adapted to reflect the NI context.

The tool also included other elements in relation to prediction of surge population and output costs associated with medicine requirements, however these features were not used.

The regional database was clinically reviewed by the Critical Care Network Northern Ireland and HSC Trusts (ICU pharmacists and pharmacy procurement leads) to ensure that data closely mirrored current regional practice, given the evolving nature of the pandemic. Subsequent feedback and updated real-world data were incorporated to further refine the database.

\section{RESULTS}

The regional database, including the elements derived from the Borthwick, Barton and Graham-Clarke 2020 tool, was developed to produce a model for calculating approximate critical care drug requirements, which underwent regional consultation. The current model considers the whole ICU population, that is, level 1, level 2 and level 3 patients. ${ }^{5}$ This was the preferred approach as the length of drug treatment and ICU stay consider both patient transition between levels of care and any overlap of individual drug treatments. In addition to average dosages of critical care drugs, the current model formulae consider four different elements:

- Percentage uptake of drug class.

- Percentage usage within drug class

- Average length of ICU stay (days).

- Average treatment duration for each drug (days).

Table 1 shows the patient and treatment characteristics assumptions used in the model to inform critical drug requirements. The ICU population uptake (\%) and average treatment length (days) for each therapeutic group was derived from the original suggested uptake data (Borthwick, Barton and GrahamClarke, 2020) and further adjusted according to real-world usage data from both local and national sources. The ICU population uptake allows for differentiation between levels of ICU patient and the differing treatment requirements of patients. The average length of treatment with a particular drug can help project critical drug requirements per patient based on predicted average length of ICU stay. This considers the fact that patients may not require treatment with a particular drug for the full length of their ICU admission. For example, using the data in table 1, it is estimated that only $50 \%$ of patients will require treatment with a vasopressor for 5 days based on a typical COVID-related ICU stay of 12.4 days. Changing any one of the variables in table 1 automatically alters the requirement output of critical care drugs
Table 1 Patient and treatment characteristics assumptions used to inform critical care drug requirements

\begin{tabular}{lll}
\hline & \multicolumn{2}{l}{$\begin{array}{l}\text { Typical length of COVID-related } \\
\text { stay=12.4 days }\end{array}$} \\
\cline { 2 - 3 } $\begin{array}{l}\text { ICU population } \\
\text { uptake }\end{array}$ & $\begin{array}{l}\text { Average treatment } \\
\text { length }\end{array}$ \\
\hline $\begin{array}{l}\text { CRRT (Continuous Renal Replacement } \\
\text { Therapy) }\end{array}$ & $20 \%$ & 7 days \\
Vasopressors & $50 \%$ & 5 days \\
\hline Vasopressor adjunct (vasopressin) & $10 \%$ & 5 days \\
\hline Sedation & $100 \%$ & 9 days \\
\hline Neuromuscular blockade (maintenance) & $85 \%$ & 8 days \\
\hline Neuromuscular blockade (intubations) & $85 \%$ & 1 day \\
\hline Care bundle compliance & $100 \%$ & 12.4 days \\
\hline Enteral feed & $100 \%$ & 12.4 days \\
\hline Bronchodilators & $100 \%$ & 7 days \\
\hline IV fluids & $100 \%$ & 7 days \\
\hline ICU, & & \\
\hline
\end{tabular}

$\mathrm{ICU}$, intensive care unit.

and can be adjusted as necessary in response to the COVID-19 population requirements.

Figure 1 shows a small selection of critical care drugs (Column A) that have been entered into the model, highlighting the neuromuscular blocker (NMB) drug group as an example. Clinically reviewed average daily doses are given in milligrams $(\mathrm{mg})$ for each drug in column B and ICU population uptake of NMB is $85 \%$ in column C.

Column D shows the percentage usage split within a therapeutic group, which considers first-line treatment choice and second-line choice, and so on, which has been adapted to reflect current regional practice. Cisatracurium is the preferred agent within the NMB therapeutic group as shown by the percentage usage split (70\%), however this can be easily adjusted depending on local preferred drug use or availability of stock. This usage split can also be a live working tool, for example, to support pharmacy procurement leads to decide which drugs Trusts should use or conserve during the COVID-19 pandemic. Column E shows the average treatment length for each drug for a typical COVIDrelated length of stay of 12.4 days.

In the current model, the only variable requiring input on a regular basis is the patient population or surge number. An example of how the model can be used to project critical drug output for an arbitrary predicted surge number of 90 ICU patients is given in table 2 .

Column F shows daily requirement of drug (mg) based on a surge number of 90 . Column $G$ shows the daily surge output (mg), factoring in the percentage uptake (column C) and percentage usage split (column D) from figure 1, that is, column $\mathrm{G}=$ column $\mathrm{F} \times($ column $\mathrm{C} \times$ column $\mathrm{D})$. Finally, the surge output requirement for a full ICU stay is given in column $\mathrm{H}$, that is, surge output/day (column G) $\times$ average treatment length (column E) from figure 1 .

Collection and monitoring of these data will be part of the ongoing refinement process of this agile model, meaning adjustments can be easily made in response to the evolving COVID-19 pandemic.

\section{APPLICATION}

The model has wide application. It has been used regionally to map critical care drug requirements to available stock in both Trusts and wholesalers/suppliers. This has enabled the identification of treatment capacity for these medicines regionally, both 


\begin{tabular}{|l|c|c|c|c|}
\hline \multicolumn{1}{|c|}{ A } & B & C & D & E \\
\hline Critical drug & $\begin{array}{c}\text { Daily dose/ } \\
\text { patient (mg) }\end{array}$ & $\begin{array}{c}\text { ICU population } \\
\text { uptake }\end{array}$ & $\begin{array}{c}\text { Usage split in } \\
\text { medicine group }\end{array}$ & $\begin{array}{c}\text { Average treatment } \\
\text { length (days) }\end{array}$ \\
\hline Norepinephrine & 40 & $50 \%$ & $90 \%$ & 5 \\
\hline Atracurium & 1500 & $85 \%$ & $10 \%$ & 8 \\
\hline Cisatracurium & 600 & $85 \%$ & $70 \%$ & 8 \\
\hline Rocuronium & 1450 & $85 \%$ & $20 \%$ & 8 \\
\hline Propofol & 6000 & $100 \%$ & $100 \%$ & 9 \\
\hline Midazolam & 150 & $100 \%$ & $50 \%$ & 9 \\
\hline Morphine & 150 & $100 \%$ & $50 \%$ & 9 \\
\hline Alfentanil & 80 & $100 \%$ & $50 \%$ & 9 \\
\hline Fentanyl & 6 & $100 \%$ & $0 \%$ & 9 \\
\hline
\end{tabular}

Figure 1 A representative example of various critical care drugs with corresponding model assumptions, based on a typical COVID-related intensive care unit (ICU) stay of 12.4 days

Table 2 A model calculation for the NMB therapeutic group requirement based on the model assumptions and an arbitrary surge number of 90 patients

\begin{tabular}{llll}
\hline A & F & G & H \\
\hline Critical drug & $\begin{array}{l}\text { Daily requirement } \\
(\mathbf{m g}) / \text { surge }(\mathbf{n = 9 0})\end{array}$ & $\begin{array}{l}\text { Surge output } \\
(\mathbf{m g}) / \text { day }\end{array}$ & $\left.\begin{array}{l}\text { Surge output } \\
(\mathbf{m g}) / / C U\end{array}\right)$ \\
\hline Cisatracurium & 54000 & 32130 & 257040 \\
Atracurium & 135000 & 11475 & 91800 \\
Rocuronium & 130500 & 22185 & 177480 \\
\hline
\end{tabular}

$\mathrm{ICU}$, intensive care unit; NMB, neuromuscular blocker.

currently and for projected surges, expressed as both the number of critical care patient stock days and total number of patients treated for the duration of their ICU stay. An example of how calculated projected drug requirement (expressed as singles) can be mapped to available stock from Trusts and wholesalers is shown in table 3 .

Data have been used in the preparation of weekly situation reports for submission to the Regional Critical Care Medicines Acute Surge Workstream for onward reporting. The situation reports include red, amber or green (RAG) ratings according to the number of stock days of both individual product lines and the therapeutic group as a whole, currently and for a projected surge. For the example shown in table 4, green indicates that there is adequate stock within the therapeutic group to fully meet the needs of critical care for more than 14 days, even though individual product lines within the group may be amber (7-14 stock days) or red (less than 7 stock days).

A further application example is the utilisation of the \% usage split data within each therapeutic class for procurement planning and preparedness in Trusts. The \% usage split data can inform discussions and support Trust pharmacy procurement leads to plan first-line product selection and use within individual Trusts, based on requirements and stock availability. For example, when a drug turns amber according to the RAG rating (ie, $7-14$ stock days of that agent are available), the $\%$ usage split of that drug is adjusted to zero or reduced to conserve and the $\%$ usage split for the other drug options in the therapeutic class are increased according to available stock, to achieve a green RAG rating. Agreement can then be reached on first-line and secondline choices for individual Trusts. This approach facilitates the consistent use of a particular agent first line in individual Trusts, and minimises the risk of using various alternative agents at short notice as a consequence of supply constraints. In addition, it achieves an effective regional approach to manage key drugs in times of constraint based on patient need.

\section{DISCUSSION}

COVID-19 is an emerging pandemic and widespread and unprecedented efforts to optimise patient care are ongoing and are being delivered at pace. The process developed to estimate critical care drug requirements represents a robust and agile starting point in the journey to inform regional procurement planning and preparedness in response to the COVID-19 pandemic. Given that this is a new virus, the existing evidence base to inform and predict critical care drug requirements is limited. Other than the unpublished tool developed in response to the H1N1 swine influenza pandemic in 2009, updated for COVID-19 (Borthwick, Barton and Graham-Clarke, 2020), the authors are not aware of any other published tools to estimate critical care drug requirements to inform procurement planning and preparedness in a pandemic. The process developed will evolve and be refined based on real-world data as they become available. Measures are currently being introduced to gather further real-world data. The current model assumptions

\begin{tabular}{|c|c|c|c|c|c|}
\hline Standard product description & $\begin{array}{l}\text { Projected requirement } \\
\text { (singles)/ ICU stay } \\
\text { (12.4 days) }\end{array}$ & $\begin{array}{l}\text { Trust stock } \\
\text { (singles) }\end{array}$ & $\begin{array}{l}\text { Wholesale } \\
\text { stock (singles) }\end{array}$ & $\begin{array}{l}\text { Total stock } \\
\text { (singles) }\end{array}$ & $\begin{array}{l}\text { No. of patients treatable with } \\
\text { available stock ( } 12.4 \text { day ICU } \\
\text { stay) }\end{array}$ \\
\hline Atracuriumbesilate $250 \mathrm{mg} / 25 \mathrm{~mL}$ solution for injection vials & 12 & 50 & 50 & 100 & 8.3 \\
\hline Atracuriumbesilate $25 \mathrm{mg} / 2.5 \mathrm{~mL}$ solution for injection ampoules & 114 & 1000 & 2000 & 3000 & 26.3 \\
\hline Atracuriumbesilate $50 \mathrm{mg} / 5 \mathrm{~mL}$ solution for injection ampoules & 57 & 3000 & 4000 & 7000 & 122.8 \\
\hline
\end{tabular}

\footnotetext{
The approximate number of patients that can be treated with available stock can be calculated based on the treatment assumptions shown in table 1.The stock data is for
} illustration purposes only. 
Table 4 An example section of the situation report showing red, amber or green (RAG) ratings according to the number of stock days of both individual product lines and the therapeutic group as a whole, currently and for an arbitrary projected surge of 90 patients

Neuromuscular blocking agents (NMBAs)

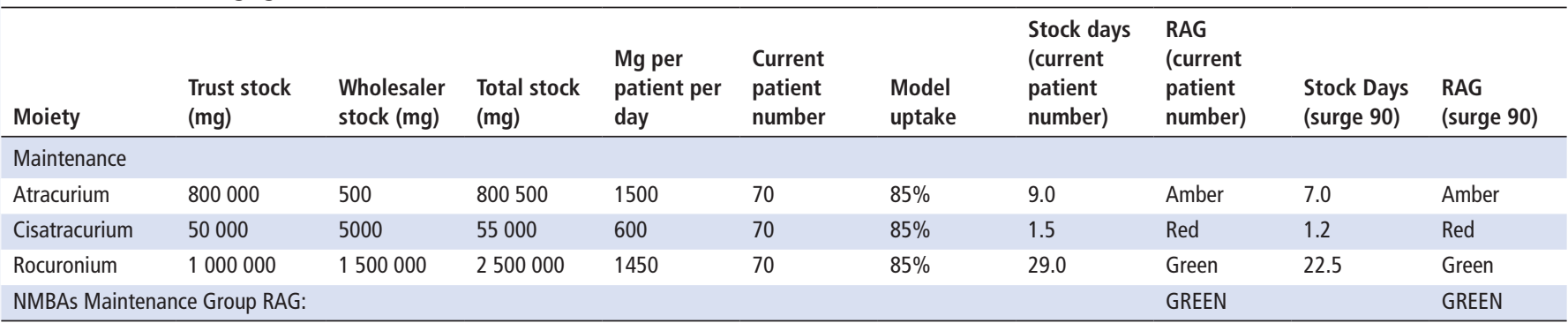

The stock data are for illustration purposes only.

were formulated to reflect the initial surge of the COVID-19 pandemic in NI. However the evolving course of the pandemic will be monitored and the assumptions can be adapted, as necessary, to reflect changing requirements.

The focus of the current model was key critical care drugs required in the COVID-19 pandemic, however, the model is transferrable to other therapeutic classes and settings and has the potential to assist in informing medicine planning and preparedness in future epidemics/pandemics. For example, the model is currently being used in palliative care and drugs, doses, $\%$ uptake, \% usage split and typical duration of treatment have been reviewed and agreed by the Regional Palliative Medicine Group and NI Specialist Palliative Care Pharmacist Group.

The process developed has been recognised by Cathy Harrison, Chief Pharmaceutical Officer at the Department of Health, commenting I very much welcome the development of the supply and demand model for critical care medicines and I support its use for managing and monitoring other groups of essential medicines and healthcare supplies at risk of potential shortages. The model provided essential information and assurance during the response to COVID-19 and I commend all those involved in its development'.

\section{CONCLUSION}

The process developed represents a collaborative and robust approach to assist in informing regional critical care drug requirements in response to the COVID-19 pandemic. Further

\section{What this paper adds}

What is already known on this subject

- The COVID-19 pandemic has presented one of the greatest challenges to healthcare worldwide.

- There has been an unprecedented global demand on supportive medicines, particularly in critical care.

- Given that this is a new virus, the existing evidence base to inform and predict critical care drug requirements is limited.

\section{What this study adds}

- The process developed is a collaborative and robust approach to assist in informing regional critical care drug requirements in response to the COVID-19 pandemic.

- The model is transferrable to other therapeutic classes and settings and can assist in informing medicine planning and preparedness in future epidemics/pandemics. application has been demonstrated in regional procurement planning and preparedness. It is anticipated that the complexity and robustness of the model will increase and will be further refined based on evolving real-world data.

\section{Limitations}

The model assumes all cases are adults as only adult doses and adult ICU occupancy data have been included.

\section{Twitter Rachel Huey @MOICNI and Michael G Scott @drmichaelscott1}

Acknowledgements The authors thank: Critical Care Network Northern Ireland, the Regional Pharmaceutical Procurement Service, in particular Noel Dunn, the Regional Pharmacy System Manager, Diane Miller, Trust ICU Pharmacists, Trust Pharmacy Procurement Leads and Chris Garland (Senior Principal Pharmaceutical Officer (Acting), Department of Health).

Contributors $\mathrm{AH}$ and $\mathrm{RH}$ coordinated and delivered the project and drafted the manuscript. MGS provided direction and advice throughout the project. AF provided clinical advice. MGS and AF reviewed the manuscript. All authors read and approved the final manuscript. Other individuals who contributed to the project have been mentioned in the acknowledgements.

Funding The authors have not declared a specific grant for this research from any funding agency in the public, commercial or not-for-profit sectors.

Competing interests None declared.

Patient consent for publication Not required.

Provenance and peer review Not commissioned; internally peer reviewed.

Data availability statement All data relevant to the study are included in the article or uploaded as supplementary information.

Open access This is an open access article distributed in accordance with the Creative Commons Attribution Non Commercial (CC BY-NC 4.0) license, which permits others to distribute, remix, adapt, build upon this work non-commercially, and license their derivative works on different terms, provided the original work is properly cited, an indication of whether changes were made, and the use is noncommercial. See: http://creativecommons.org/licenses/by-nc/4.0/.

\section{ORCID iDs}

Anita Hogg http://orcid.org/0000-0002-4369-305X

Rachel Huey http://orcid.org/0000-0002-1500-7593

\section{REFERENCES}

1 Coronavirus.data.gov.uk. Coronavirus (COVID-19) cases in the UK, 2020. Available: https://coronavirus.data.gov.uk/ [Accessed 28 Apr 2020].

2 BNF Joint Formulary Committee. British National formulary (online) London: BMJ group and pharmaceutical press. Available: http://www.medicinescomplete.com [Accessed 28 Apr 2020].

3 ICNARC. ICNARC report on COVID-19 in critical care 17 April 2020, 2020

4 Department of Health. Daily Covid-19 figures - 28 April 2020, 2020. Available: https:// www.health-ni.gov.uk/news/daily-covid-19-figures-28-april-2020 [Accessed $28 \mathrm{Apr}$ 2020].

5 Department of Health. Comprehensive critical care: a review of adult critical care services (White Paper). London: The Stationery Office, 2000. 